\title{
Assessment of Ergonomic Aspects in Dental Clinic Rooms
}

Eliel Soares Orenha ${ }^{a,{ }^{*}}$, Suely Mutti Carvalho Naressi ${ }^{\mathrm{a}}$, Symone Cristina Teixeira ${ }^{\mathrm{a}}$, Enzo Rosetti ${ }^{\mathrm{a}}$, José $^{\prime}$ Carlos Plácido da Silva ${ }^{\mathrm{b}}$, Mariana Falcão Bormio ${ }^{\mathrm{b}}$, Artemis Rodrigues Fontana ${ }^{\mathrm{b}}$, Marcelo de Castro Meneghim $^{\mathrm{c}}$, Angélica Cristiane Búlio Soares ${ }^{\mathrm{c}}$

${ }^{a}$ Social and Infant Clinics Department, Univ Est Paulista - UNESP/São José dos Campos Dental School, Av. Eng. Fco. José Longo777, Jardim São Dimas, CEP 12245-000, São José dos Campos-São Paulo, Brazil.

${ }^{b}$ Department of Industrial Design, Univ Est Paulista - UNESP/Faculty of Architecture, Arts and Communication, Av Eng Luiz Edmundo Carrijo Coube, $n^{\circ}$ 14-01, CEP 17.033-360, Vargem Limpa, Bauru - São Paulo, Brazil.

${ }^{c}$ Department of Social Dentistry, University of Campinas - UNICAMP, Piracicaba Dental School, P.O. Box 52, , CEP 13414-903, Piracicaba-São Paulo, Brazil

\begin{abstract}
This study aimed to describe how to evaluate and quantify the ergonomic satisfaction level of dental clinics rooms. Requirements for design, production and selection of dental equipment as described in ISO/TC-106/SC-6-N-411, support more comprehensive studies for an ergonomic evaluation and ergo design of the dental workstations. It was created a checklist of ergonomics requirements which is supported by Standards ISO/FDI and acquired by mean of a literature review. According to information exposed at the document of the Ergonomics Society of Dental Ergonomics - ESDE we can consider that the elaboration of an ergonomic evaluation protocol regard to the dental workstation is an important demand for the ergonomics, particularly in relation to the performance of the ergonomic design which presents qualified to assist to dental equipment manufactures. By this means, the identification of the evaluation factors pointed in ISO/TC 106/SC 6 N 411 offers the basic information to the process of elaboration of this protocol addressed by the described general guidelines.
\end{abstract}

Keywords: ergonomics, design, dental equipment.

\footnotetext{
- ${ }^{*}$ Corresponding author. E-mail: eliel@fosjc.unesp.br. Eng Francisco José Longo, no 777 - Jardim São Dimas. São José dos Campos SP, Brazil. CEP: 12245-000, Fone: +55 01239479344
} 


\section{The dentist's work}

Dentist's postural complaints in dental practice are well-known subject for discussion. Provoked initially by the working position, more specifically due to the adoption of inadequate working postures during patient treatment, the musculoskeletal pains that arise in dental practice is an issue of study, above all, in the ergonomics area.

The greater emphasis to the patient's well-being, which ensures more comfort during the treatment time can be the main reason for the loss of focus in dental practice as a dental workstation and consequently contributes for dentist's work in an unhealthful way. According to Hokwerda [3], "... dental equipments are not being projected or built to give to the dentists the opportunity to work inside of acceptable physiologic limits. Even so, it is vitally important to consider the ergonomic design in the development of the dental equipment, because, it will allow to the dentists to work in the possible healthiest way."

Considering that ergonomic design is a relatively new concept, Paschoarelli [10] exposes that "... this denomination characterizes a specific segment of the product's project development (environmental, objectual or informational), which aims to apply ergonomic knowledge to the project of technological devices in order to reach safety, comfortable, efficient, effective and acceptable interfaces systems." However, according to Delleman [1] the process of ergonomic designing is intimately linked to the methodology of ergonomic evaluation, since this makes the necessary tools available to develop an interface that adapts to the needs of the final user regarding his characteristics and the activities that he will be carried out.

In regard to the design of dental workstations recent studies contribute important scientific evidences in relation to the dentist's activity. However, in the ambit of legislation important criteria have been defined as the publication of the International Standard Project ISO/TC'S 106/SC 6 N 411 [8] which determines the standard postural position to be adopted by the professionals during dental practice. The pattern defined by this International Standard, together with studies published in this area, offers the necessary subsidies for creation of a Methodology for Evaluation of Ergonomic Aspects to be applied to the dental workstation.

With the aim of contributing for amplification of scientific knowledge in the area of dental ergonom- ics, this paper has as objective to create subsidies to assess dental equipment in line with evidence-based ergonomic criteria by means of identification of present factors in dentist's activity which interfere directly and indirectly in that activity in reference to the International Standards. These factors constitute the requirements for evaluation of the dental workstation according to general guidelines so that the process of development of an assessment of ergonomic aspects will be addressed to the dental workplace. We presume that this process will deliver the basic tools for ergo-design.

\section{Prerequisites}

Hokwerda [3] concluded that in the international literature about $65 \%$ of dentists present complaints of musculoskeletal disorders, which vary in severity but are always related to uncomfortable feelings, pain and obstruction during work and loss of work time. Alarming data were published in regard to the skeletal occurrence of muscle pain suffered by dentistry students in San Francisco where the students' percentage that presented this pain in the period of the first to the third year increased for approximately $70 \%$ including the persistence, duration and frequency of the pain. Another point to be considered is the increase of the number of female dentists in most countries. Here the concern is that women are more prone to a variety of chronics musculoskeletal pain than males.

Justified by this context as presented by Hokwerda [2-4] this thematic has received high importance in researches which recognize and characterize the dental workstation as inadequate from the ergonomic point of view, inadequate for professional's performance due the fact of forcing peculiar static postures.

ISO 11226:2002 [6] establishes rules for healthy work in a static working posture. This Standard shows that is important to adopt a more dynamic posture. To achieve a healthy posture during dental practice it is necessary that the dentist moves himself for another position in order to reach a better vision in a straight and symmetrical posture. This fact constantly happens due to the need of performance in another of the 5 dental faces or in another area of the mouth.

To work in a healthy way requires that dentists work in a proper posture which it is at the same time upright, symmetrical, stable, balanced, and fundamentally dynamic and active, prone to the movement, 
not only static posture. Due to all requirements, a large literature research was coordinated by Hokwerda [2] in the scope of ESDE's activities by which a document was written that defines the "guidelines and requirements for the adoption of a healthy work posture during the patient's treatment". This document is considered a theoretical benchmark for dental ergonomics and provides the theory and base for an international standard project to determine a healthy way for the work in dental practice. Additionally the ISO 6385:2004(E)-“Ergonomic principles in the design of work systems" [5] provides the guidelines for ESDE (European Society of Dental Ergonomics) to prepare the document "Ergonomic requirements for dental equipment. Guidelines and recommendations for designing, constructing and selecting dental equipment". This document served as a basis for the proposal of the International Standard Project ISO/TC'S 106/SC 6 N 411[8].

\section{Stages and phases of the ergonomic intervention}

The definition of the standard healthy postures for dentists offers the necessary base for ergonomic in-

\section{ISO/TC 106/SC 6 N 411 - Ergonomic requirements for dental equipment. Guidelines and recommendations for designing, constructing and selecting dental equipment.}

The goal is to define the functional man-machine system for the dentist on the basis of a product system analysis starting from human functions in relation to current anthropometric data and existing rules.

ISO/TC 106/SC 6 N 411 [8] goal "is to define a functional man-machine system for the dentist on the basis of a product system analysis starting from human functions in relation to the current anthropometric data and existing rules." This information is therefore provided for everybody who is associated with the use of dental equipment.

tervention as described by Moraes and Mont'alvão [9]. This intervention involves aspects of ergonomic design which fundamentally leans on the assessment of ergonomic criteria according to the steps as showed in Table 1.

Table 1. Ergonomic Intervention (Moraes and Mont'Galvão, 2000)

\begin{tabular}{|c|c|}
\hline Stage & Description \\
\hline Ergonomic Appreciation & $\begin{array}{l}\text { Constitutes the exploratory phase, which understands the mapping of the ergonomic problems of the context in } \\
\text { subject. It consists of the systematization of the man-task-machine system and in the delimitation of the ergo- } \\
\text { nomic problems relative to postural, informational, job, cognitive, communicational, interactional, displace- } \\
\text { ment, movement, operational, space, physical and environmental aspects; }\end{array}$ \\
\hline Ergonomic Diagnosis & $\begin{array}{l}\text { Allows to deepen the prioritized problems and to test predictions. In agreement with the focus of the work, } \\
\text { they are made the analysis macro-ergonomic and/or the analysis of the task of the man-task-machine systems }\end{array}$ \\
\hline Ergonomic design & $\begin{array}{l}\text { Aim to adapt the workstations and equipment and tools to the user's physical and cognitive characteristics. It } \\
\text { includes the determination of exact arrangement and the interaction of interfaces, of the subsystems and com- } \\
\text { ponents instrumental information, triggering, communication, of interaction, instruction, movements, spaces } \\
\text { and physical-environment }\end{array}$ \\
\hline $\begin{array}{l}\text { Evaluation, validation } \\
\text { and/or ergonomic tests }\end{array}$ & $\begin{array}{l}\text { Return the arguments and proposals and project's alternative to the user. Comprehend simulations and evalua- } \\
\text { tions through test's models }\end{array}$ \\
\hline $\begin{array}{l}\text { Ergonomic Specification } \\
\text { and Optimization }\end{array}$ & Comprehends the project revision after its evaluation \\
\hline
\end{tabular}

Systematic knowledge of work content, which was verified in the assessment of ergonomic aspects of dental equipment, is pre-requisite for the diagnosis and preparation of an ergonomic project or ergonomic design.

In general, a demand for an ergonomic intervention implies simultaneously to know the way of performance of the ergonomist. Consequently, most of the companies prefer to begin with the aspect of ap- preciation by the professional society. However, knowledge of work content and 'ergonomic appreciation' determines a new demand. This can understand the diagnosis or the more diagnosis the ergonomic design.

Consequently, the steps described below correspond to general guidelines for the process of drawing up an ergonomic evaluation protocol, directed to assess the dental workstation taking into considera- 
tion the elements appraisable pointed by ISO/TC

\section{General guidelines for the structuring process of the ergonomic evaluation protocol.}

- Identification of the factors pointed by ISO/TC 106/SC 6 N 411 [8] which should be considered in the evaluation protocol;

- Comparison of the ISO factors with the pointed factors by Hokwerda [2-4];

- Exact determination of the individual factors;

- Registration of the appeared variables of the dentist's interaction with its position, by means of photo, video and technical assessment;

- Delimitation of the pertinent variables for structuring of the protocol evaluation;

- Graphic creation of the factors and its evaluation variables;

- Structuring of the protocol;

- Structuring of the model for answers tabulation and report elaboration;

- Pre-test for application of the previous protocol model;

- Validation

\section{Final Remarks}

According to information exposed by the ESDE document "Ergonomic requirements for dental equipment - Guidelines and recommendations for designing, constructing and selecting dental equipment" we consider that the elaboration of an ergonomic evaluation protocol in regard to the dental work station is an important demand for ergonomics. Particularly in relation to the performance of the ergonomic design which presents qualified assistance to dental equipment manufacturers. By this means, identification of evaluation factors pointed out in ISO/TC 106/SC $6 \mathrm{~N} 411$ offers the basic information to start the process of elaboration of this protocol addressed by the described general guidelines.

\section{6/SC 6 N 411 [8].}

[1] DELLEMAN NJ, HASLEGRAVE CM, CHAFFIN DB. Working Postures and Movements. Tools for Evaluation and Engineering. London, New York, Washington: CRC Press LLC, 2004

[2] HOKWERDA O; de RUIJTER R, SHAW S. Adopting a healthy sitting working posture during patient treatment. Optergo. July-2006. Available in:http://www.optergo.com/uk/images/Adopting. pdf. Accessed in: 09/07/2008

[3] HOKWERDA O. Practical Positioning. DPR Europe. May-2006. Available in:

http://www. dpreu-

rope.com/dpreurope/Trends+in+Dentistry/PracticalPositioning/ArticleStandard/Article/detail/337327. Accessed in: 09/07/2008

[4] HOKWERDA O. Sit up and take note! Professor Oene Hokwerda discusses how dental equipment can be designed to prevent (and not cause) chronic pain for dentists. DPR Europe. April 2007. Available in: http://www.dpreurope.com/dpreurope/Practice+Essent ials\%3A+Ergonomics/Sit-up-and-take-

note/ArticleStanard/Article/detail/425963. Accessed in: 09/07/2008

[5] ISO Standard 6385 "Ergonomic principles in the design of work systems"

[6] ISO Standard 11226 "Ergonomics - Evaluation of static working postures"

[7] ISO Standard 9241-9 Ergonomic requirements for office work with visual display terminals (VDT's) - Part 9: Requirements for non-keyboard input devices

[8] ISO/TC 106/SC 6 N 411. Ergonomic requirements for dental equipment: Guidelines and recommendations for designing, constructing and selecting dental equipment. 2006

[9] de MORAES A, MONT'ALVÃO C. Ergonomia: conceitos e aplicações. Rio de Janeiro, 2000, $2^{\text {nd }}$ edition

[10] PASCHOARELLI LC. Os impactos da ergonomia nas metodologias de design. Ago/2007.

Available in: http://www.designbrasil.org.br/portal/opiniao/exibir.jh tml? idArtigo $=1092$

Acknowledgment: We tanks to Fapesp for supporting this research project.

\section{References}

